\title{
Influence of Age, Risk Factors, and Cardiovascular and Renal Disease on Arterial Stiffness: Clinical Applications
}

\author{
Athanase Benetos, Bernard Waeber, Joseph Izzo, Gary Mitchell, \\ Lawrence Resnick, Roland Asmar, and Michel Safar
}

Age is the main clinical determinant of large artery stiffness. Central arteries stiffen progressively with age, whereas peripheral muscular arteries change little with age. A number of clinical studies have analyzed the effects of age on aortic stiffness. Increase of central artery stiffness with age is responsible for earlier wave reflections and changes in pressure wave contours. The stiffening of aorta and other central arteries is a potential risk factor for increased cardiovascular morbidity and mortality. Arterial stiffening with aging is accompanied by an elevation in systolic blood pressure (BP) and pulse pressure (PP). Although arterial stiffening with age is a common situation, it has now been confirmed that older subjects with increased arterial stiffness and elevated PP have higher cardiovascular morbidity and mortality.

Increase in aortic stiffness with age occurs gradually and continuously, similarly for men and women. Crosssectional studies have shown that aortic and carotid stiffness (evaluated by the pulse wave velocity) increase with age by approximately $10 \%$ to $15 \%$ during a period of 10 years. Women always have 5\% to $10 \%$ lower stiffness than men of the same age.

\section{Age and Arterial Stiffness}

Using various assessment techniques, an age-dependent increase in arterial stiffness in both healthy and diseased populations has been described. It has been shown that in vivo aortic stiffness decreases sharply with age in the first decade of life, reaching a minimum at 10 years of age, and thereafter increasing with age in both genders. ${ }^{1}$ This agedependent increase in central arterial stiffness is independent of mean blood pressure (BP) or the presence of other risk factors. ${ }^{2}$ Using multivariate models, age is the major
Although large artery stiffness increases with age independently of the presence of cardiovascular risk factors or other associated conditions, the extent of this increase may depend on several environmental or genetic factors. Hypertension may increase arterial stiffness, especially in older subjects. Among other cardiovascular risk factors, diabetes type 1 and 2 accelerates arterial stiffness, whereas the role of dyslipidemia and tobacco smoking is unclear. Arterial stiffness is also present in several cardiovascular and renal diseases. Patients with heart failure, end stage renal disease, and those with atherosclerotic lesions often develop central artery stiffness. Decreased carotid distensibility, increased arterial thickness, and presence of calcifications and plaques often coexist in the same subject. However, relationships between these three alterations of the arterial wall remain to be explored. Am J Hypertens 2002;15:1101-1108 @ 2002 American Journal of Hypertension, Ltd.

Key Words: Arteriosclerosis, arterial aging, hypertension, pulse pressure. clinical determinant of aortic stiffness, a finding confirmed in several populations in different countries. ${ }^{1,3,4}$

The underlying basis for these age-dependent changes is still incompletely understood. Pathologically, fracture and fragmentation of the elastin fibers after repetitive stress cycles, with consequent dilation and stiffening have been observed..$^{5-7}$ A more dynamic, cellular ionic basis for age-related changes in arterial compliance have also been described. ${ }^{8}$ Thus, 1) cytosolic-free calcium levels increase and free magnesium levels reciprocally decrease with age
Received July 10, 2002. First decision July 11, 2002. Accepted July 11, 2002.

From the IPC Center and INSERM U258 (AB), Paris, France; CHUV Lausanne (BW), Lausanne, Switzerland; State University of New York (JI), Buffalo, New York; Cardiovascular Engineering Center (GM), Dover Massachusetts; Hypertension Center, New York Presbyterian
Hospital/Cornell University, New York, New York; Institut Cardiovasculaire (RA), Paris, France; and Hôpital Broussais (MF), Paris, France.

Address correspondence and reprint requests to Dr. A. Benetos, IPC Center, 6/14 ruela Perouse, 75116 Paris, France; e-mail: benetos@ ccr.jussieu.fr 
in circulating red cells, platelets, skeletal muscle, and brain $^{8-11}$;2) direct magnetic resonance imaging (MRI)assessd aortic distensibility/stiffness is closely related to steady-state intracellular free magnesium levels ${ }^{8}$; and 3) furthermore, when intracellular free magnesium levels are incorporated into a multivariate model, the age dependence of aortic stiffness is no longer significant. ${ }^{8}$

The effects of aging are different on proximal, predominantly elastic arteries, compared to distal, predominantly muscular arteries. ${ }^{5,12,13}$ Central arteries stiffen progressively with age, whereas stiffness of muscular arteries changes little with age..$^{5}$ A number of clinical studies have analyzed the effects of age on aortic stiffness, mainly with the method of pulse wave velocity (PWV). The increase of central artery stiffness with age is responsible for earlier wave reflections and changes in pressure wave contours. Kelly et $\mathrm{al}^{14}$ observed that wave reflections were responsible for an increase of about $25 \%$ in pulse pressure (PP) between age 30 and 60 years. The effects of age on peripheral artery stiffness are less pronounced; it has been shown that the peripheral PWV (carotid-radial or femoral-tibial) changes with age are approximately two to three times less frequent than those of the central aorta. ${ }^{4,7} \mathrm{Sim}$ ilar results have been observed when local cross-sectional distensibility coefficients were evaluated at the sites of the carotid and femoral arteries of the same subjects. Carotid artery distensibility was strongly correlated with age, whereas no such correlation was observed at the site of the femoral artery. 5,15

Increase in aortic stiffness with age occurs gradually and continuously, similarly for men and women. ${ }^{15}$ Crosssectional studies have shown that aortic PWV increases with age by approximately $0.1 \mathrm{~m} / \mathrm{sec}$ per year (about $1 \%$ ). ${ }^{3}$ Similar changes were observed at the site of the carotid artery. ${ }^{5}$ However, some studies have suggested that increase in large artery stiffness follows a nonlinear quadratic evolution, with a more pronounced increase after the age of 55 years. ${ }^{16,17}$ This result corroborates the well-known epidemiologic observation of an increasing prevalence of systolic hypertension, the main clinical manifestation of large artery stiffness, after the age of 55 years. ${ }^{18}$

Although large artery stiffness increases with age independently of the presence of cardiovascular risk factors or other associated conditions, the extent of this increase may depend on several environmental or genetic factors. Studies have shown that PWV increased less with age in populations with low salt diet than in those with high sodium chloride consumption. ${ }^{19}$ The role of other environmental factors is less documented. Breithaupt-Grogler et $\mathrm{al}^{20}$ have shown that people with high garlic consumption had a less pronounced increase in arterial stiffness with age. We have recently shown that the relationship between age and aortic PWV was influenced by the angiotensin II type $1\left(\mathrm{AT}_{1}\right)$ genotypes, ${ }^{17}$ indicating that genetic variants may influence the development of arterial stiffness with age.
In the past, vascular stiffening and increase in systolic and pulse pressure have been considered as a part of normal aging and no treatment for these alterations has been proposed. However, although arterial stiffening is a common situation, it has now been confirmed that older subjects with increased arterial stiffness and elevated systolic and PP have higher cardiovascular morbidity and mortality. ${ }^{21-25}$ Therefore, large artery stiffening can be considered as a marker of arterial age, and should be considered as a major risk factor for cardiovascular events.

\section{Hypertension and Arterial Stiffness}

In subjects with hypertension, the principal structural modification of the vessel wall is hypertrophy of the medial layer. ${ }^{12,26}$ In younger hypertensive subjects, the alterations of the mechanical properties result mainly from the elevated BP itself, as reduced carotid compliance and distensibility disappear in isobaric conditions. ${ }^{27}$ However, in some other territories such as the femoral artery or even the thoracic aorta, intrinsic changes in stiffness (ie, increased stiffness in isobaric conditions) may be observed. ${ }^{28}$ In subjects with hypertension, active mechanisms within the arterial wall are certainly involved because, at the site of peripheral muscular arteries such as the radial artery, diameter is unchanged despite the elevated $B P$, whereas in central arteries, the diameter is increased in proportion with the level of BP. ${ }^{26}$

Among the elderly hypertensives, medial hypertrophy is associated with a considerable development of the extracellular matrix of the media and even of the adventitia. This histomorphometric pattern is associated with reduced compliance and distensibility independent of BP level. ${ }^{29}$ Again, these changes are observed at the site of central, but not peripheral, arteries. Finally, both with aging and hypertension, endothelium alterations are noted. Although endothelium alterations may differ markedly in the hypertensive and in the aging process according to the topography of the vessels, ${ }^{30,31}$ a major role is attributed to changes in nitric oxide (NO) production or release. The NO release is of particular importance for peripheral muscular arteries in which NO and vasoconstrictive compounds in relation with vascular smooth muscle cells are in constant interaction. ${ }^{30,31}$ The renin-angiotensin-aldosterone system (RAAS) activity may also play a key role in the regulation of arterial stiffness in hypertensives. We have shown that in hypertensives but not in normotensives, the angiotensin II type $1\left(\mathrm{AT}_{1}{ }^{1166} \mathrm{~A} / \mathrm{C}\right)^{32}$ receptor and aldosterone synthase $\left(\mathrm{CYP}_{11 B_{2}}{ }^{-344} \mathrm{~T} / \mathrm{C}\right)$ gene variants $^{33}$ are significant determinants of arterial stiffness. These results suggest that neurohormonal systems, such as the RAAS may be have synergistic effects with mechanical factors (increase in BP) on large artery's stiffness. 


\section{Effects of Hypertension and Age on Central and Peripheral Pressure Waveforms}

Ejection of blood into the aorta generates a pressure wave that is propagated to other arteries throughout the body. This forward traveling (incident) pressure wave is reflected at all points of structural and functional discontinuity of the arterial tree, generating a reflected wave traveling backward toward the ascending aorta. ${ }^{12}$ Incident and reflected pressure waves are in constant interaction and are summed up in a measured pressure wave. The final amplitude and shape of the measured PP wave are determined by the amplitude of the forward wave and the phase relationship (the timing) between the component waves. The timing of incident and reflected pressure waves depends on the PWV, the traveling distance of pressure waves, the level of reflection coefficients, and the duration of ventricular ejection. The desirable timing is mainly disrupted by increased PWV in relation to arterial stiffening. With increased PWV, the reflecting sites appear closer to the ascending aorta and the reflected waves occur earlier, being more closely in phase with incident waves in this area. The earlier return means that the reflected wave impacts on the central arteries during systole rather than diastole, thus amplifying aortic pressure during systole and reducing aortic pressure during diastole. ${ }^{12,26}$ This dual alteration of systolic and diastolic BP with a resulting increase in pulse pressure is observed during both the hypertensive and the aging processes, although there are important differences between the two clinical situations. With hypertension, there is, in the younger population, a persistence of the PP gradient, which is the reason that PP remains higher in peripheral than in central arteries, but with a resetting of the gradient toward higher values of mean arterial pressure. ${ }^{26}$ This hemodynamic pattern is related to the normal amplitude of the forward pressure wave, whereas reflection coefficients are elevated as a consequence of arteriolar constriction. ${ }^{12}$ On the other hand, with aging, the PP gradient tends to disappear, due to a more rapid stiffening with age of central, but not peripheral arteries, with a resulting increase in the amplitude of the forward pressure wave and the existence of low reflection coefficients. These differences in BP behavior in the hypertensive and the aging process may be due to a number of factors in addition to arterial stiffness. Most of them are combined in old hypertensive subjects. First, the timing of wave reflections is influenced by the characteristics of the reflection coefficients of the pressure wave, which are principally located at the origin of resistant vessels. It is important to note that the control of peripheral vascular resistance, and hence of small arteries, is modified with age and hypertension, particularly through endothelial or neurohumoral changes. ${ }^{12}$ Second, the location of the same reflection sites may be substantially modified with aging and hypertension, in relation with the age- and pressure-induced increase in the caliber of arteries and with the age-induced increase in the length of large vessels. ${ }^{12,28}$ Third, pathologic alterations may also produce reflection sites closer to the heart, as shown in the presence of calcified plaques, particularly at the site of arterial bifurcations (aorta; carotid and femoral arteries; origin of renal arteries). ${ }^{12,26,34}$ When examined together, these examples indicate that both increased arterial stiffness and alteration of wave reflections contribute independently to the predominant or selective increase of PP observed with age and hypertension and especially their combination.

\section{Diabetes and Arterial Stiffness}

Even among normal subjects, fasting blood glucose values are closely related to arterial stiffness, whether assessed on the basis of direct MRI-based measurements of aortic distensibility, ${ }^{8}$ or using more indirect computerized pulse waveform analysis of the radial artery ${ }^{35}$ - the higher the blood glucose, the stiffer (less distensible or compliant) the artery. These more recent findings were preceded by earlier observations of more obviously abnormal vascular stiffness among hyperglycemic diabetic individuals. Although hyperglycemia is a common feature in all diabetics, and although approximately $90 \%$ of clinical diabetes is of the type 2, non-insulin dependent form, type 1 and type 2 diabetes will be considered separately as certain etiologic and clinical differences may distinguish them.

\section{Diabetes, Type 1}

A number of studies have reported that type 1 diabetic patients have stiffer arteries than normal subjects. ${ }^{36-45}$ However, several major factors, such as the duration of the illness, the degree of obtained control under therapy, and the complications of the disease, may influence the effects of type 1 diabetes on large arteries. Lehmann et $\mathrm{al}^{38}$ analyzed the aortic compliance in recent onset child patients. Their results contradicted reports in the literature and showed that the young type 1 diabetic patients evaluated within 1 year of diagnosis have aortas ranging up to 78\% more distensible than their sex- and age-matched nondiabetic controls. On the other hand, Kool et $\mathrm{al}^{39}$ reported reduced arterial distensibility only at the femoral artery level but not at the site of carotid and brachial arteries in uncomplicated diabetic adults. Ahlgren et al ${ }^{40}$ reported increase of aortic and carotid stiffness in diabetic women but not in diabetic men. Similar results were reported more recently by Ahlgren ${ }^{41}$ who showed a significant correlation between aortic stiffness and duration of diabetes and autonomic dysfunction in diabetic women. Also, an Italian study ${ }^{42}$ showed that type 1 diabetes was characterized by diffuse arterial wall stiffening and thickening even in patients without any clinical vascular complications, showing that large artery stiffness and hypertrophy are early markers of vascular damage. More recently, Lambert et $\mathrm{al}^{43}$ showed that acute hyperglycemia had no effects on the arterial wall properties, whereas an association between arterial stiffness and heart rate vari- 
ability has been described by Jensen-Urstad et al. ${ }^{44} \mathrm{Fi}-$ nally, when all the data published on this subject are considered, all but one of the studies showed a decrease of arterial distensibility in type 1 diabetic patients. These arterial abnormalities, which have been reported even in young patients, children and adolescents, seem to be more pronounced at the aortic and the lower limb levels, with a significant correlation with the duration of diabetes.

\section{Diabetes, Type 2}

Several studies showed an increase in arterial stiffness in type 2 diabetic patients, and positive correlations between arterial stiffness and free fatty acid and insulin levels. ${ }^{36,45-54}$ It was also found that arterial stiffness was best predicted on the basis of age and area under the blood glucose curve. These results suggested that noninvasive investigation of arteries may be useful in the evaluation of presymptomatic stages of atherosclerosis in diabetes. Lehmann et $\mathrm{al}^{38}$ analyzed the aortic compliance in type 2 diabetic patients using measurements of PWV. Their results support findings by other groups and showed that type 2 diabetic patients have significantly stiffer aortas than their age- and sex-matched nondiabetic controls. Megnien et $\mathrm{al}^{50}$ studied the effects of non-insulin-dependent diabetes mellitus on the physical properties of the brachial artery in men. Their results showed that in comparison to control subjects, diabetic patients had lower operating and isobaric compliance. In the control and diabetic groups, fasting glucose correlated negatively with measured and isobaric compliance. Elsewhere, Amar et $\mathrm{al}^{51}$ studied the influence of glucose metabolism on carotid-femoral PWV in untreated hypertensive patients with elevated waist/hip ratio. Their results showed higher PWV values in diabetics and glucose intolerant patients, compared to those with normal glucose levels. A positive correlation between PWV and fasting glycemia was noted.

On the whole, the published data showed higher stiffness in type 2 diabetic patients and also in normal subjects with a positive family history of diabetes. ${ }^{52-54}$ Associations between PWV and fasting glucose and insulin levels, as well as insulin resistance, have been described. One study reported that these arterial abnormalities are more evident at the aortic and the lower limb levels than in the upper limbs. More specific studies, which take into consideration the duration of the disease, its treatments, and the degree of control obtained under treatment, are needed to understand the mechanisms involved between arterial stiffness and type 2 diabetes. Studies should also be extended to the problem of insulin resistance and its treatment.

\section{Dyslipidemia and Arterial Stiffness}

On the basis of experimental and clinical studies, it has been reported that excess cholesterol substantially alters the endothelial function, leading to a decreased relaxation of the arterial vessels. ${ }^{55}$ The defect has been described mainly in atherosclerotic patients but also in asymptomatic subjects with hypercholesterolemia. ${ }^{56}$ Whether this abnormality is associated with an increased stiffness of the arterial wall in humans remains to be demonstrated and for the moment the results of the literature are controversial.

Data from animals have shown an unexpected increase in aortic distensibility and compliance at an early stage of diet-induced experimental atherosclerosis, which subsequently decreased (ie, the aortas became stiffer) as atheroma progressed in the later stages of the disease. ${ }^{57,58}$ These findings have been partly confirmed by other investigators who reported a decrease of aortic distensibility in animals exposed to grossly elevated plasma cholesterol levels with severe experimental atherosclerosis. ${ }^{59,60}$

Lehmann et $\mathrm{al}^{61}$ investigated young patients with heterozygous familial hypercholesterolemia and sex- and age-matched normocholesterolemics. They showed that patients with familial hypercholesterolemia had significantly more distensible aortas than the control subjects, with significant positive correlations between compliance and cholesterol, low-density lipoprotein cholesterol (LDL) and duration of disease, and a negative correlation between aortic compliance and high-density lipoprotein cholesterol (HDL). Interestingly, the same researchers ${ }^{62,63}$ showed that adults with familial hypercholesterolemia had significantly less distensible aortas than normocholesterolemics, with an inverse correlation between LDL-cholesterol and aortic distensibility in pooled data, age and LDL-cholesterol being the best independent predictors of aortic distensibility. Some studies reported increased rigidity of the aortic wall in groups of hypercholesterolemic subjects. ${ }^{64}$ Giannattasio et al ${ }^{65}$ observed a marked reduction in radial artery compliance in subjects in a small population of patients with familial hypercholesterolemia. Interestingly in that study, a long-term treatment of hypercholesterolemic patients with a statin was able to increase arterial compliance. However, studies from different populations ${ }^{66,67}$ failed to demonstrate any association between aortic stiffness (evaluated with the PWV) and total plasma cholesterol. In these population studies, the different fractions of lipoproteins were not evaluated. Kupari et al ${ }^{68}$ even described a negative relationship between arterial stiffness and LDL-cholesterol levels.

\section{Effects of Smoking on Arterial Stiffness}

Although smoking is known to alter the arterial wall, particularly the endothelial function, and to accelerate atheromatosis in several arterial territories, little is known about the influence of tobacco consumption on arterial stiffness. Failla et al ${ }^{69}$ showed that in smokers without any overt cardiovascular disease, acute cigarette smoking reduced distensibility in both medium and large arteries. It has also been demonstrated that cigarette smoking increased PWV in both normotensive and hypertensive 
subjects. ${ }^{70}$ The acute effects of smoking were also investigated in chronic smokers by several investigators. ${ }^{71-75}$ All of these studies showed that acute smoking significantly decreased carotid and brachial distensibility, and increased BP. However, no basal differences related to long-term effects of smoking were found, compared to nonsmokers. ${ }^{71,76}$ In middle-aged women, no association between aortic PWV and history of smoking was observed.

\section{Arterial Stiffness in Heart Failure Patients}

In congestive heart failure (CHF), several researchers showed, through the use of invasive methods, the presence of abnormalities of large conduit vessels, and more specifically that physical properties of the aortic wall are significantly altered ${ }^{77}$ In fact, conduit artery distensibility affects the pulsatile component of afterload and contributes to impaired left ventricular function. This may be partly reflected by the relative reduction of BP with heart failure, where as PWV remains high. Nonetheless, few studies using noninvasive methods have been conducted to evaluate the role of large arteries in heart failure, and mostly to determine whether comparable abnormalities to those seen at the ascending aorta are present in other parts of the arterial tree.

All but two of the studies showed that arterial compliance and distensibility evaluated at the aortic, carotid, iliac, or brachial artery levels are impaired in different populations of patients with CHF. ${ }^{78-80}$ In addition, hyperhemic flow was associated with increases in distensibility in healthy subjects but not in CHF patients, whereas sublingual glyceryl trinitrate induced similar effects in both groups. ${ }^{80}$ These results point to the role of the endothelium on the arterial properties in CHF and imply that endothelium derived relaxing factor mediated increases in distensibility are impaired in CHF patients. Concurrently, Giannattasio et $\mathrm{al}^{81}$ showed that at the radial artery level, baseline compliance is altered in patients with severe CHF but not in those with mild CHF. However, the postischemic increase in compliance was blunted in both mild and severe $\mathrm{CHF}$, suggesting that arterial compliance and its modulation are impaired in CHF. The same investigators reported that the impaired arterial compliance occurring in CHF was increased by treatment with angiotensin converting enzyme (ACE) inhibitors. ${ }^{82}$ They concluded that addition of an ACE inhibitor could counteract the adverse effects of reduced compliance in patients with $\mathrm{CHF}$ such as increased cardiac work and oxygen consumption, decreased coronary perfusion, and altered baroreflex.

The exact mechanism of these alterations is not clear. Further studies are needed to assess the mechanisms of increased arterial stiffness in patients with heart failure (altered flow dilatation, increased activity of the sympathetic system).

\section{End-Stage Renal Diseases and Arterial Stiffness}

Clinical and epidemiologic studies have shown a high prevalence of systolic hypertension in end-stage renal disease (ESRD). The principal factor responsible for increased systolic BP and PP in ESRD patients is increased arterial stiffness with increased PWV and early wave reflections. ${ }^{83,84}$ Indeed, in comparison with age- and mean blood pressure-matched nonuremic patients, the arterial stiffness is greater in ESRD, especially in younger uremic subjects. The stiffening is more pronounced in the aorta than in peripheral arteries. It has recently been shown that in ESRD patients aortic stiffness was an independent risk factor for total mortality and cardiovascular morbidity and mortality. ${ }^{85}$ Increased arterial stiffness was found to be associated with the presence of arterial calcifications and a low HDL-cholesterol level, but not with other metabolic or hormonal disturbances commonly observed in ESRD. ${ }^{84}$ Several studies that include ESRD patients indicate that sodium overload may induce arterial stiffening independently of BP changes. In ESRD patients, a positive relationship between interdialytic body weight gain and aortic PWV was observed, supporting the potential role of sodium excess. Besides the increase in peripheral systolic BP and BP, the most obvious consequence of arterial stiffening in ESRD patients is an early return of wave reflections to the aorta and the disappearance of aortic-to-peripheral pressure amplification. ${ }^{86}$ This phenomenon, which normally occurs after the sixth decade, appears already during the fourth decade in ESRD patients and means that for a similar brachial systolic BP, the aortic systolic BP is higher in ESRD patients than in nonuremics. The second factor associated with an early return of wave reflections in ESRD patients is a shorter effective length of the arterial tree. ${ }^{86-88}$ This is related to a shorter body size, principally shorter body height, resulting from malnutrition and growth retardation frequently observed in azotemic children and adults with nephropathies starting in childhood. With a comparable arterial stiffness and peripheral resistance, ESRD patients with short body height have an increased effect of wave reflections on aortic pressure. Low body height was also found to be associated with cardiovascular risk in men and women in the general population. Whether arterial stiffness and altered wave reflection occur at the early phase of renal diseases still remain unknown.

\section{Atherosclerotic Alterations and Arterial Stiffness}

The best example associating atherosclerosis and arterial stiffness (arteriosclerosis) is observed in patients with arteriosclerosis of the lower limbs. ${ }^{89,90}$ Increased systolic and PP are commonly observed in these patients, whereas mean arterial pressure, vascular resistance, and ventricular 
ejection remain largely within the normal range. Systemic and forearm arterial compliance are significantly reduced. In these subjects, increased PP is significantly and independently associated with the reduction in the vasodilating arteriolar properties of the diseased limbs, as evaluated with plethysmography. ${ }^{89}$ Coronary ischemic disease has been found to be substantially associated with increased aortic stiffness. ${ }^{91}$ Although an increased incidence of elevated systolic BP was not reported in populations of subjects with ischemic heart disease, these subjects frequently only have a wide PP and decreased diastolic pressure-time index in association with the already mentioned aortic stiffening. Experimentally, decreased aortic compliance participates in and aggravates the myocardial ischemia observed in the presence of stenosis of the coronary artery. ${ }^{92}$

Stenosis of the internal carotid artery is frequently associated with systolic hypertension. ${ }^{93,94}$ In subjects with carotid endarterectomy, a significant increase in systolic $\mathrm{BP}$ variability is also observed, particularly during the night. ${ }^{95}$ Decreased carotid distensibility, increased arterial thickness, and presence of calcifications and plaques often coexist in the same subjects. ${ }^{93-95}$ However, the relationships between these three alterations of the arterial wall, that is, atheromatosis (plaques), hypertrophy (increased media thickness), and stiffness (decreased compliance), remains to be explored.

\section{References}

1. Laogun AA, Gosling RG: In vivo arterial compliance in man. Clin Phys Physiol Meas 1982;3:201-212.

2. Relf IR, Lo CS, Myers KA, Wahlquist ML: Risk factors for changes in aorto-iliac arterial compliance in healthy men. Arteriosclerosis 1986;6:105-108.

3. Asmar R, Benetos A, London G, Hugue C, Weiss Y, Topouchian J, Laloux B, Safar M: Aortic distensibility in normotensive, untreated and treated hypertensive patients. Blood Pressure 1995;4:48-54.

4. Avolio AP: Pulse wave velocity and hypertension, in Safar ME (ed): Arterial and Venous Systems in Essential Hypertension. Martinus Nijhoff, 1987, pp 133-152.

5. Nichols WV, O'Rourke MF: McDonald's blood flow in arteries, in Arnold E. (ed): Theoretical, Experimental and Principles, 3 ed. London, Melbourne, Auckland, 1990, pp 77-142, 216-269, 283269, 398-437.

6. Dobrin PB: Vascular mechanics. Handbook of Physiology, in John T. Sheperd, François M. Abboud (volume ed.): Stephen R. Geiger (executive ed.): Section 2: The cardiovascular System. Volume III. Peripheral Circulation and Organ Blood Flow, Part I. American Physiological Society, Bethesda, Maryland, 1983, pp 65-102.

7. Cox RH: Basis for the altered arterial wall mechanics in the spontaneously hypertensive rat. Hypertension 1981;3:485-495.

8. Resnick LM, Militianu D, Cunnings AJ, Pipe JG, Evelhoch JL, Soulen RL: Direct magnetic resonance determination of aortic distensibility in essential hypertension: relation to age, abdominal visceral fat, intracellular free magnesium. Hypertension 1997;30: 654-659.

9. Barbagallo M, Gupta RK, Dominguez LJ, Resnick LM: Cellular ionic alterations with age: relation to hypertension and diabetes. J. Am Geriatrics Soc 2000;48:1111-1116.

10. Barbagallo M, Dominguez L, Resnick LM: Effects of aging on serum ionized and cytosolic free calcium: relation to hypertension and diabetes. Hypertension 1999;34:902-906.

11. Petersen B, Schroll M, Christiansen C, Tranavol I: Serum and erythrocyte magnesium in normal elderly Danish people. Acta Med Scand 1977;201:31-34.

12. Benetos A, Laurent S, Hoeks AP, Boutouyrie P, Safar M: Arterial alterations with aging and high blood pressure. A noninvasive study of carotid and femoral arteries. Arterioscler Thromb 1993;13:9097.

13. Laurent S, Hayoz D, Trazzi S, Boutouyrie P, Waeber B, Omboni S, Brunner HR, Mancia G, Safar MJ: Isobaric compliance of the radial artery is increased in patients with essential hypertension. J Hypertens 1993;11:89-98.

14. Kelly R, Hayward C, Avolio A, O'Rourke M: Non-invasive determination of age-related changes in the human arterial pulse. Circulation 1989;80:1652-1659.

15. Van der-Heijden-Spek JJ, Staessen JA, Fagard RH, Hoeks AP, Struijker-Boudier HA, Van Bortel LM: The effect of age on brachial artery wall properties differs from the aorta and is gender dependent: a population study. Hypertension 2000;35:637-642.

16. Nagai Y, Fleg JL, Kemper MK, Rywik TM, Earley CJ, Metter EJ: Carotid arterial stiffness as a surrogate for aortic stiffness: relationship between carotid artery pressure-strain elastic modulus and aortic pulse wave velocity. Ultrasound Med Biol 1999;25:181-188.

17. Lajemi M, Labat C, Gautier S, Lacolley P, Safar M, Asmar R, Cambien F, Benetos A: Angiotensin II type 1 receptor ${ }^{-153} \mathrm{~A} / \mathrm{G}$ and ${ }^{1166} \mathrm{~A} / \mathrm{C}$ gene polymorphisms and increase in aortic stiffness with age in hypertensive subjects. J Hypertens 2001;19:407-413.

18. Franklin SS, Gustin W, Wong ND, Larson MG, Weber MA, Kannel WB, Levy D: Hemodynamic patterns of age-related changes in blood pressure. The Framingham Heart Study. Circulation 1997;96: 308-315.

19. Avolio A: Genetic and environmental factors in the function and structure of the arterial wall. Hypertension 1995;26:23-37.

20. Breithaupt-Grogler K, Ling M, Boudoulas H, Belg G: Protective effect of chronic garlic intake on elastic properties of aorta in the elderly. Circulation 1997;96:2649-2655.

21. Benetos A, Safar M, Rudnichi A, Smulyan H, Richard JL, Ducimetiere P, Guize L: Pulse pressure: a predictor of long term cardiovascular mortality in a French male population. Hypertension 1997; 30:1410-1415.

22. Mitchell GF, Moye LA, Braunwald E, Rouleau J-L, Bernstein V, Geltman EM, Flaker GC, Pfeffer M, for the SAVE Investigators: Sphygmomanometric determined pulse pressure is a powerful independent predictor of recurrent events after myocardial infarction in patients with impaired left ventricular function. Circulation 1997; 96:4254-4260.

23. Franklin SS, Khan SA, Wong ND, Larson MG, Levy D: Is pulse pressure useful in predicting risk for coronary heart disease? The Framingham Heart Study. Circulation 1999;100:354-360.

24. Benetos A, Zureik M, Morcet $\mathrm{J}$, Thomas $\mathrm{F}$, Bean $\mathrm{K}$, Ducimetière $\mathrm{P}$, Safar M, Guize L: A decrease in diastolic blood pressure combined with an increase in systolic blood pressure is associated with a higher cardiovascular mortality in men. J Am Coll Cardiol 2000; 35:673-680.

25. Laurent S, Boutouyrie P, Asmar R Gautier I, Laloux B, Guize L, Ducimetiere P, Benetos A: Aortic stiffness is an independent predictor of all-cause and cardiovascular mortality in hypertensive patients. Hypertension 2001;37:1236-1241.

26. Safar ME, London GM: The arterial system in human hypertension, in Swales JD (ed): Textbook of Hypertension. London, Blackwell Scientific, 1994, pp. 85-102.

27. Laurent S, Caviezel B, Beck L, Girerd X, Billaud E, Boutouyrie P, Hoeks A, Safar M: Carotid artery distensibility and distending pressure in hypertensive humans. Hypertension 1994;23 (Part II): 878-883.

28. Liu ZR, Ting CT, Zhu SX, Yin FC: Aortic compliance in human hypertension. Hypertension 1989;14:129-136. 
29. Blacher J, London GM, Safar ME, Mourad JJ: Influence of age and end-stage renal disease on the stiffness of carotid wall material in hypertension. J Hypertens 1999;17:237-244.

30. Küng CF, Lüscher TF: Different mechanisms of endothelial dysfunction with aging and hypertension in rat aorta. Hypertension 1995;25:194-200.

31. Moncada S, Palmer RMJ, Higgs BA: Nitric oxide: physiology, pathophysiology and pharmacology. Pharmacol Rev 1991;43:109142 .

32. Benetos A, Gautier S, Ricard S, Topouchian J, Asmar R, Poirier O, Larosa E, Guize L, Safar M, Soubrier F, Cambien F: Influence of angiotensin converting enzyme and angiotensin II type 1 receptor gene polymorphisms on aortic stiffness in normotensive and hypertensive patients. Circulation 1996;94:698-703.

33. Pojoga L, Gautier S, Blanc H, Guyene TT, Poirier O, Cambien F, Benetos A: Genetic determination of plasma aldosterone levels in essential hypertension. Am J Hypertens 1998;11:856-860.

34. Labouret O, Achimastos A, Benetos A, Safar M, Housset E: L'hypertension artérielle des amputés traumatiques. Press Med 1983;21:1349-1354.

35. Resnick LM, Militianu D, Cunnings AJ, Pipe JG, Evelhoch JL, Soulen RL, Lester MA: Pulse waveform analysis of arterial compliance in hypertension: relation to other techniques, age, and metabolic variables. Am J Hypertens 2000;13:1243-1249.

36. Woolam GL, Schnur PL, Vallbona C, Hoff HE: The pulse wave velocity as an early indicator of atherosclerosis in diabetic subjects. Circulation 1962;25:533-539.

37. Okada M, Matsuto T, Satoh S, Igarashi S, Baba M, Sugita O, Okada M: Role of pulse wave velocity for assessing autonomic nervous system activities in reference to heart rate variability. Med Inform (Lond) 1996;21(Suppl 1):81-90.

38. Lehmann ED, Gosling RG, Sönksen PH: Arterial wall compliance in diabetes. Diabetic Med 1992;9:114-119.

39. Kool MJ, Lambert J, Stehouwer CD, Hoeks AP, Struijker Boudier HA, Van Bortel LM: Vessel wall properties of large arteries in uncomplicated IDDM. Diabetes Care 1995;18:618-624.

40. Ahlgren AR, Lane T, Wollmer P, Sonesson B, Hansen F, Sundkvist G: Increased arterial stiffness in women, but not in men, with IDDM. Diabetologia 1995;38:1082-1089.

41. Ahlgren AR, Sundkvist G, Wollmer P, Sonesson B, Lanne T: Increased aortic stiffness in women with type 1 diabetes mellitus is associated with diabetes duration and autonomic nerve function. Diabet Med 1999;16(Suppl 4):291-297.

42. Giannattasio C, Failla M, Piperno A, Grappiolo A, Gamba P, Paleari F, Mancia G: Early impairment of large artery structure and function in type 1 diabetes mellitus. Diabetologia 1999;42:987-994.

43. Lambert J, Smulders RA, Aarsen M, Gallay FP, Stehouver CD: The acute effect of hyperglycaemia on vessel wall properties. Scand J Clin Lab Invest 1997;57:409-414.

44. Jensen-Urstad K, Reichard P, Jensen-Urstad M: Decreased heart rate variability in patients with type 1 diabetes mellitus is related to arterial wall stiffness. J Intern Med 1999;245:57-61.

45. Scarpello JH, Martin TR, Ward JD: Ultrasound measurements of pulse-wave velocity in the peripheral arteries of diabetic subjects. Clin Sci 1980;58:53-57.

46. Relf IR, Lo CS, Myers KA, Wahlqvist ML: Risk factors for changes in aorto-iliac arterial compliance in healthy men. Arteriosclerosis 1986;6:105-108.

47. Lo CS, Relf IR, Myers KA, Wahlqvist ML: Doppler ultrasound recognition of preclinical changes in arterial wall in diabetic subjects: compliance and pulse-wave damping. Diabetes Care 1986;9: 27-31.

48. Wahlqvist ML, Relf IR, Myers KA, Lo CS: Diabetes and macrovascular disease: risk factors for atherogenesis and non-invasive investigation of arterial disease. Hum Nutr Clin Nutr 1984;38:175184

49. Wahlqvist ML, Lo CS, Myers KA, Simpson RW, Simpson JM:
Putative determinants of arterial wall compliance in NIDDM. Diabetes Care 1988;11:787-790.

50. Megnien JL, Simon A, Valensi P, Flaud P, Merli I, Levenson J: Comparative effects of diabetes mellitus and hypertension on physical properties of human large arteries. J Am Coll Cardiol 1992;20: $1562-1568$

51. Amar J, Chamontin B, Pelissier M, Garelli I, Salvador M: Influence of glucose metabolism on nycthemeral blood pressure variability in hypertensives with an elevated waist-hip ratio. A link with arterial distensibility. Am J Hypertens 1995;8:426-428.

52. Tanokuchi S, Okada S, Ota Z: Factors related to aortic pulse-wave velocity in patients with non-insulin-dependent diabetes mellitus. J Int Med Res 1995;23:423-430.

53. Hopkins KD, Lehmann ED, Jones RL, Turay RC, Gosling RG: A family history of NIDDM is associated with decreased aortic distensibility in normal healthy young adult subjects. Diabetes Care 1996;19:501-503.

54. Emoto M, Nishizawa Y, Kawagishi T, Maekawa K, Hiura Y, Kanda H, Izumotani K, Shoji T, Ishimura E, Inaba M, Okuno Y, Morh H: Stiffness indexes beta of the common carotid and femoral arteries are associated with insulin resistance in NIDDM. Diabetes Care 1998;21:1178-1182.

55. Henry PD: Inappropriate coronary vasomotion: excessive constriction and insufficient dilation, in Sperakakis N (ed.) Physiology and Pathophysiology of the Heart. 1989, Kluwer Academic Publishers, pp 975-991.

56. Creager MA, Gallagher SJ, Girerd XJ, Coleman SM, Dzau VJ, Cooke JP: Arginine improves endothelium-dependent vasodilation in hypercholesterolemic humans. J Clin Invest 1992;90:1248-1253.

57. Gosling RG, Hayes JA, Segre-Mackkay W: Induction of atheroma in cockerels as a model for studying alterations in blood flow. $\mathrm{J}$ Atheroscler Res 1969;9:47-56.

58. Newman DL, Gosling RG, Bowden NLR: Changes in aortic distensibility and area ratio with the development of atherosclerosis. Atherosclerosis 1971;14:231-240.

59. Farrar DJ, Green HP, Bond MG, Wagner WP, Gobbee RA: Aortic pulse wave velocity, elasticity and composition in non-human primate model of atherosclerosis. Circ Res 1978;43:52-62.

60. Manning PJ, Clarkson TB: Development, distribution, and lipid content of diet-induced atherosclerotic lesions of rhesus monkeys. Exp Mol Pathol 1972;17:38-54.

61. Lehmann ED, Watts GF, Fatemi-Langroudi B, Gosling R: Aortic compliance in young patients with heterozygous familial hypercholesterolemia. Clin Sci 1992;83:717-721.

62. Lehmann E, Watts GF, Gosling R: Aortic distensibility and hypercholesterolemia. Lancet 1992;340:1171-1172.

63. Lehmann E, Hopkins K, Parker J, Gosling R: Hyperlipidaemia, hypertension and coronary heart disease. Lancet 1995;345:862-863.

64. Relf IRN, Lo CS, Myers KA, Wahlwvist MI: Risk factors for changes in aortic-iliac arterial compliance in healthy men. Arteriosclerosis 1986;6:105-108.

65. Giannattasio C, Mangoni AA, Failla M, Carugo S, Stella ML, Stefanoni P, Grassi G, Vergani C, Mancia G: Impaired radial artery compliance in normotensive subjects with familial hypercholesterolemia. Atherosclerosis 1996;124:249-260.

66. Avolio AP, Deng FQ, Li WQ, Luo YF, Huang ZD, Xing LF, O'Rourke MF: Effects of aging on arterial distensibility in populations with high and low prevalence of hypertension: comparison between urban and rural communities in China. Circulation 1985; 71:202-210.

67. Dart AM, Lacombe F, Yeoh JK, Cameron JD, Jennings GL, Laufer E, Esmore DS: Aortic distensibility in patients with isolated hypercholesterolemia, coronary disease or cardiac transplant. Lancet 1991;338:270-273

68. Kupari M, Hekali P, Keto P, Poutanen VP, Tikkanen MJ, Standerstkjold-Nordenstam CG: Relation of aortic stiffness to factors modifying the risk of atherosclerosis in healthy people. Arterioscler Thromb 1994;14:386-394. 
69. Failla M, Grappiolo A, Carugo S, Calchera I, Giannattasio C, Mancia G: Effects of cigarette smoking on carotid and radial artery distensibility. J Hypertens 1997;15:1659-1664.

70. Levenson J, Simon AC, Cambien FA, Beretti C: Cigarette smoking and hypertension. Factors independently associated with blood hyperviscosity and arterial rigidity. Arteriosclerosis 1987;7(Suppl 6): S572-S577.

71. Kool MJ, Struijker Boudier HA, Reneman RS, Van Bortel LM: Short-and-long-term effects of smoking on arterial wall properties in habitual smokers. J Am Coll Cardiol 1993;22:1881-1886.

72. Stefanadis C, Tsiamis E, Vlachopoulos C, Stratos C, Toutouzas K, Pitsavos C, Marakas S, Boudoulas H, Toutouzas P: Unfavorable effect of smoking on the elastic properties of the aorta. Circulation 1997;95:31-38.

73. Stefanadis C, Vlachopoulos C, Tsiamis E, Diamantopoulos L, Toutoujas K, Giatzakos N, Vaina S, Tsekouras D, Toutoujas P: Unfavorable effects of passive smoking on aortic function in men. Ann Interm Med 1998;128:426-434.

74. Brunel P, Girerd X, Laurent S, Pannier B, Safar M: Acute changes in forearm haemodynamics produced by cigarette smoking in healthy normotensive non-smokers are not influenced by propranolol or pindolol. Eur J Clin Pharmacol 1992;42:143-146.

75. Berlin I, Cournot A, Renout P, Duchier J, Safar M: Peripheral haemodynamic effects of smoking in habitual smokers. A methodological study. Eur J Clin Pharmacol 1990;38:57-60.

76. Taquet A, Bonithon-Kopp C, Simon A, Levenson J, Scarabin Y, Malmejac A, Ducimetiere P, Guize L: Relations of cardiovascular risk factors to aortic pulse wave velocity in asymptomatic middleaged women. Eur J Epidemiol 1993;9:298-306.

77. Simonson E, Nakagawa K: Effect of age on pulse wave velocity and "aortic ejection time" in healthy men and in men with coronary artery disease. Circulation 1960;22:126-129.

78. Arnold JM, Marchiori GE, Imrie JR, Burton GL, Pflugfelder PW, Kostuk WJ: Large artery function in patients with chronic heart failure. Circulation 1991;84:2418-2425.

79. Lage SG, Kopel L, Monachini MC, Medeiros CJ, Pileggi F, Polak JF, Creager MA: Carotid arterial compliance in patients with congestive heart failure secondary to idiopathic dilated cardiomyopathy. Am J Cardiol 1994;74:691-695.

80. Ramsey MW, Goodfellow J, Jones CJ, Luddington LA, Lewis MJ, Henderson AH: Endothelial control of arterial distensibility is impaired in chronic heart failure. Circulation 1995;92:3212-3219.

81. Giannattasio C, Failla M, Stella ML, Mangoni AA, Carugo S, Pozzi M, Grassi G, Mancia G: Alterations of radial artery compliance in patients with congestive heart failure. Am J Cardiol 1995;76:381385.

82. Giannattasio C, Failla M, Stella ML, Mangoni AA, Turrini D,
Carugo S, Pozzi M, Mancia G: Angiotensin converting enzyme inhibition and radial artery compliance in patients with congestive heart failure. Hypertension 1995;26:491-496.

83. London GM, Guerin AP, Pannier B, Marchais SJ, Benetos A, Safar ME: Arterial wave reflections and increased systolic and pulse pressure in chronic uremia: study using noninvasive carotid pulse waveform registration. Hypertension 1992;20:10-19.

84. London GM, Marchais SJ, Safar ME, Genest AF, Guerin AP, Metivier F, Chedid K, London AM: Aortic and large artery compliance in end-stage renal failure. Kidney Int 1990;37:137-142.

85. Blacher J, Guerin AP, Pannier B, Marchais SJ, Safar ME, London GM: Impact of aortic stiffness on survival in end-stage renal disease. Circulation 1999;99:2434-2439.

86. Marchais SJ, Guérin A, Pannier BM, Levy BI, Safar ME, London GM: Wave reflections and cardiac hypertrophy in chronic uremia. Hypertension 1993;22:876-883.

87. Rahn KH, Barenbrock M, Hausberg M, Kosch M, Suwelack B, Witta J: Vessel wall alterations in patients with renal failure. Hypertens Res 2000;23:3-6.

88. Barenbrock M, Hansberg M, Kosch M, Kisters K, Hoeks AP, Rahn $\mathrm{KH}$ : A longitudinal study of vessel wall properties in normotensive and hypertensive renal transplant recipients. J Hum Hypertens 1988; 12:707-711.

89. Safar ME, Toto Moukouo JJ, Asmar RA, Laurent S: Increase pulse pressure in patients with arteriosclerosis obliterans of the lower limbs. Arteriosclerosis 1987;7:232-237.

90. Safar ME: Atherosclerotic hypertension: systolic hypertension and arterial compliance in patients with arteriosclerosis obliterans of the lower limbs, in Safar ME, Fouad-Tarazi F (eds): The Heart in Hypertension. Dordrecht, Kluwer Academic Publishers, 1989, pp 123-133.

91. Stefanadis C, Wooley CF, Bush CA, Kolibash Al, Boudoulas J: Aortic distensibility abnormalities in coronary artery disease. Am J Cardiol 1987;59:1300-1304.

92. Kelly R, Tunin R, Kass D: Effect of reduced aortic compliance on left ventricular contractile function and energetics in vivo. Circ Res 1992;71:490-502.

93. Arcaro G, Laurent S, Iondeau G, Hoeks AP, Safar ME: Stiffness of the common carotid artery in treated hypertensive patients. J Hypertens 1991;9:947-954.

94. Safar ME, Laurent S, Benetos A, London GM: The common carotid circulation in patients with essential hypertension. Stroke 1988;19: $1198-1202$

95. Asmar RG, Julia PL, Mascarel VL, Fabiani JN, Benetos A, Safar ME: Ambulatory blood pressure profile after carotid endarterectomy in patients with ischaemic arterial disease. J Hypertens 1994;12: 697-702. 